\title{
FT-IR/PAS Studies of Lunar Regolith Samples
}

\author{
S. Pasieczna-Patkowska ${ }^{a}$, A. DA̧Browski ${ }^{a}$, E. Robens $^{b}$ \\ AND J. RYCZKOWSKI ${ }^{a, *}$ \\ ${ }^{a}$ Faculty of Chemistry, University of Maria Curie-Skłodowska \\ pl. M. Curie-Skłodowskiej 2, 20-031 Lublin, Poland \\ ${ }^{b}$ Institut für Anorganische Chemie und Analytische Chemie \\ Johannes Gutenberg-Universität \\ Duesbergweg 10-14, D-55099 Mainz, Germany
}

\begin{abstract}
This paper describes investigations of the surface properties of lunar regolith powder samples from the Apollo 11, 12, and 16 missions, respectively. For this part of studies conducted at the Faculty of Chemistry, Maria Curie-Skłodowska University a Fourier transform infrared photoacoustic spectroscopy was applied.
\end{abstract}

PACS numbers: $82.80 . \mathrm{Gk}$

\section{Introduction}

The formation of regolith and soil on airless planetary bodies, such as Moon, asteroids, is the result of processes virtually nonexistent on Earth. The physical and chemical changes that occur to the materials at the surfaces of such airless bodies are collectively known as "space weathering" and are mainly caused by impacts of meteorites, micrometeorites, galactic and solar-wind particles, in the deep vacuum of space [1].

Between 1969 and 1972 six Apollo missions brought back 382 kilograms (the majority was delivered by Apollo 15, 16 and 17 missions) of lunar rocks, core samples, pebbles, sand, and dust from the lunar surface. The six space flights returned 2200 separate samples from six different exploration sites on the Moon [2]. The Apollo samples are handled and stored either under vacuum or in clean dry nitrogen gas (Fig. 1) at the lunar sample building of the National Aeronautics and Space Administration (NASA) Johnson Space Center.

Lunar soil and rock samples of the Apollo missions have been already examined in detail [2-4]. Planning new missions and the establishment of a manned

*corresponding author; e-mail: ryczkows@hermes.umcs.lublin.pl 


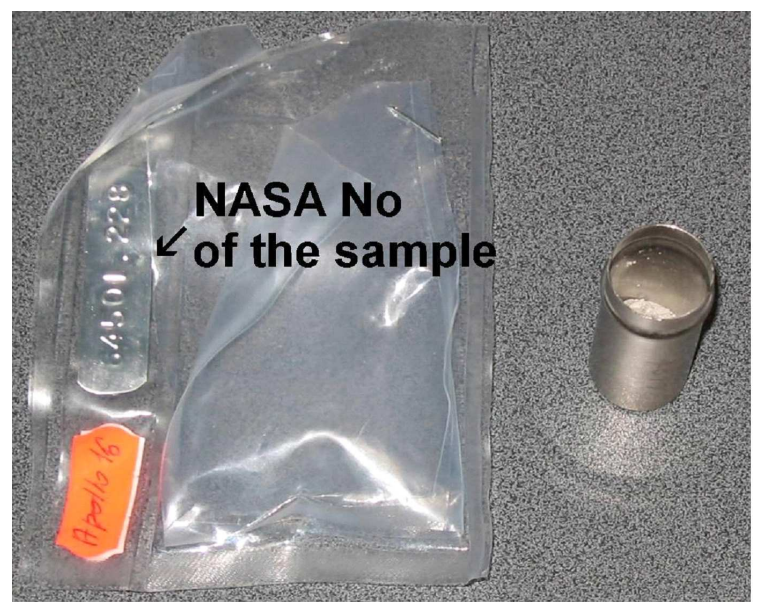

Fig. 1. Sample 64501.228 delivered by the Apollo 16 mission in an original container.

station at the Moon require some additional information. The aim of broader investigation (including this one) is to obtain parameters relevant to the capability of the Moon surface to store water in relation to the environmental conditions.

\section{Experimental}

\subsection{Samples}

Below, in Tables I and II there are included data characterizing investigated Moon regolith samples.

TABLE I

Brief description of the investigated samples [3].

\begin{tabular}{l|c|c|c|c|c}
\hline \hline Mission & $\begin{array}{c}\text { Duration } \\
\text { of the mission }\end{array}$ & Geographical area & $\begin{array}{c}\text { Type } \\
\text { of } \\
\text { area }\end{array}$ & $\begin{array}{c}\text { Total amount } \\
\text { of taken } \\
\text { samples [kg] }\end{array}$ & $\begin{array}{c}\text { Sample } \\
\text { No. }\end{array}$ \\
\hline Apollo 11 & $16-24.07 .1969$ & Mare Tranquillitatis & Mare & 21.55 & 10084.2000 \\
Apollo 12 & $14-24.11 .1969$ & Oceanus Procellarum & Mare & 34.35 & 12001.922 \\
Apollo 16 & $16-27.04 .1972$ & North of Crater Descartes & Terra & 95.71 & 64501.228 \\
\hline
\end{tabular}

\subsection{Spectroscopic measurements}

Fourier transform infrared photoacoustic spectroscopy (FT-IR/PAS) measurements were performed using Bio-Rad (Excalibur 3000MX) spectrometer and helium purged MTEC300 photoacoustic detector, over the $4000-400 \mathrm{~cm}^{-1}$. Spectra were obtained at room temperature (RT) at $4 \mathrm{~cm}^{-1}$ resolution. The spectra were normalized by computing the ratio of a sample spectrum to the spectrum of a MTEC carbon black reference material. A stainless steel cup was filled with samples (thickness $<6 \mathrm{~mm}$ ). Each phase of data collection was preceded by the 
TABLE II

Chemical composition of the lunar samples (main components) [1].

\begin{tabular}{c|c|c|c}
\hline \hline Element & Apollo 11 & Apollo 12 & Apollo 16 \\
\hline $\mathrm{Na}$ & $0.18 \%$ & $0.29 \%$ & $0.21 \%$ \\
$\mathrm{Mg}$ & $4.40 \%$ & $4.00 \%$ & $2.00 \%$ \\
$\mathrm{Al}$ & $9.51 \%$ & $3.71 \%$ & $15.13 \%$ \\
$\mathrm{Si}$ & $19.12 \%$ & $10.44 \%$ & $19.10 \%$ \\
$\mathrm{~K}$ & $0.21 \%$ & $0.13 \%$ & $<787 \mathrm{ppm}$ \\
$\mathrm{Ca}$ & $9.85 \%$ & $5.31 \%$ & $11.84 \%$ \\
$\mathrm{Ti}$ & $5.11 \%$ & $1.26 \%$ & $0.31 \%$ \\
$\mathrm{Cr}$ & $0.21 \%$ & $0.20 \%$ & $731 \mathrm{ppm}$ \\
$\mathrm{Mn}$ & $0.14 \%$ & $0.10 \%$ & $445 \mathrm{ppm}$ \\
$\mathrm{Fe}$ & $10.55 \%$ & $7.71 \%$ & $2.83 \%$
\end{tabular}

PA cell purging with dry helium for 5 min. Interferograms of 512 scans were averaged for each spectrum. Changes in absorption bands were investigated in the mid IR region.

\section{Results and discussion}

Figure 2 illustrates FT-IR/PA spectra of the investigated samples in the $4000-2600 \mathrm{~cm}^{-1}$ region. Strong, broad bands with the maxima around $3440 \mathrm{~cm}^{-1}$ are characteristic of the asymmetric $\mathrm{H}-\mathrm{O}-\mathrm{H}$ stretching vibrations. This is an indication of physically adsorbed water on the samples' surfaces.

In the range $3000-2800 \mathrm{~cm}^{-1}$ there are several low intensity bands and brief description is given below (Table III).

The presence of organic compounds containing carbon and hydrogen is an indication that all samples were slightly contaminated in the past. This is not an evidence that such compounds exist on the Moon. In the following figure (Fig. 3) there is spectral characteristic of the investigated samples in the $2000-400 \mathrm{~cm}^{-1}$ region. Bands with the maxima around $1640 \mathrm{~cm}^{-1}$ are connected with the symmetric $\mathrm{H}-\mathrm{O}-\mathrm{H}$ stretching vibrations. Weak bands located at about $1384 \mathrm{~cm}^{-1}$ and band at $1540 \mathrm{~cm}^{-1}$ (Apollo 12) can be attributed to $\mathrm{C}-\mathrm{H}$ deformation stretching. Moreover, a weak band with the maximum at $1739 \mathrm{~cm}^{-1}$ can be an indication of the presence of carbon containing oxygen organic compounds. This is an additional evidence that examined samples were contaminated.

Based on the literature data and Raman spectroscopy studies [6] it is known that the majority of the minerals found on the Moon are of the same kind as those occurring on our Earth (Table IV).

Major phases are composed mainly with silica materials. Observed vibrations in the recorded spectra (Fig. 3) should be connected with the various $\mathrm{Si}-\mathrm{O}$ 


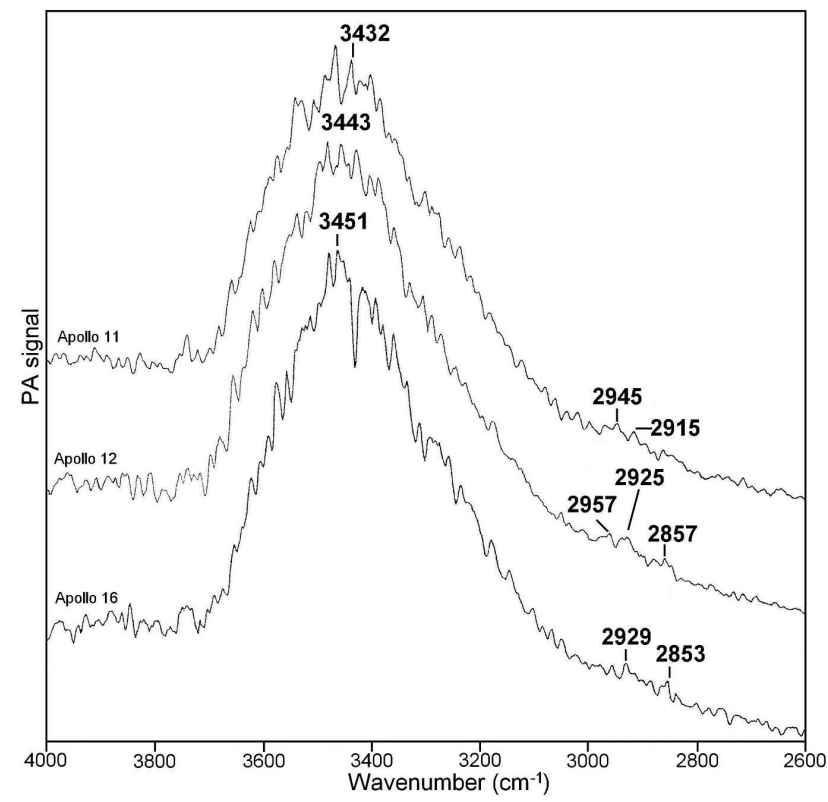

Fig. 2. FT-IR/PA spectra of Lunar regolith samples in the $4000-2600 \mathrm{~cm}^{-1}$ region.

TABLE III

Valence vibrations of $\mathrm{C}-\mathrm{H}$ in the $3000-2800 \mathrm{~cm}^{-1}$ range [5].

\begin{tabular}{c|c|c}
\hline \hline Mission & Vibration $\left[\mathrm{cm}^{-1}\right]$ & Comment \\
\hline \multirow{2}{*}{ Apollo 11 } & 2945 & $\nu_{\mathrm{as}}-\mathrm{CH}_{3}$ \\
\cline { 2 - 3 } & 2915 & $\nu_{\mathrm{as}}-\mathrm{CH}_{2}$ \\
\hline \multirow{3}{*}{ Apollo 12 } & 2957 & $\nu_{\mathrm{as}}-\mathrm{CH}_{3}$ \\
\cline { 2 - 3 } & 2925 & $\nu_{\mathrm{as}}-\mathrm{CH}_{2}$ \\
\cline { 2 - 3 } & 2857 & $\nu_{\mathrm{s}}-\mathrm{CH}_{2}$ \\
\hline \multirow{2}{*}{ Apollo 16 } & 2929 & $\nu_{\mathrm{as}}-\mathrm{CH}_{2}$ \\
\cline { 2 - 3 } & 2853 & $\nu_{\mathrm{s}}-\mathrm{CH}_{2}$ \\
\hline
\end{tabular}

${ }^{*} \nu_{\text {as }}$ and $\nu_{\mathrm{s}}$ - asymmetric and symmetric stretching vibrations, respectively

stretching. In the recorded spectra maxima located in the range $1100-900 \mathrm{~cm}^{-1}$ can be attributed to $\nu_{\text {as }}(\mathrm{Si}-\mathrm{O}-\mathrm{Si})$ and $\mathrm{Si}-\mathrm{O}$ stretching. The vibration with the maximum at about $730 \mathrm{~cm}^{-1}$ can be described as $\nu_{\mathrm{s}}(\mathrm{Si}-\mathrm{O}-\mathrm{Si})$ stretching. A weak band at $628 \mathrm{~cm}^{-1}$ can be described as $\delta(\mathrm{Si}-\mathrm{O}-\mathrm{Si})$ or could be an indication of the magnetite presence [7]. 


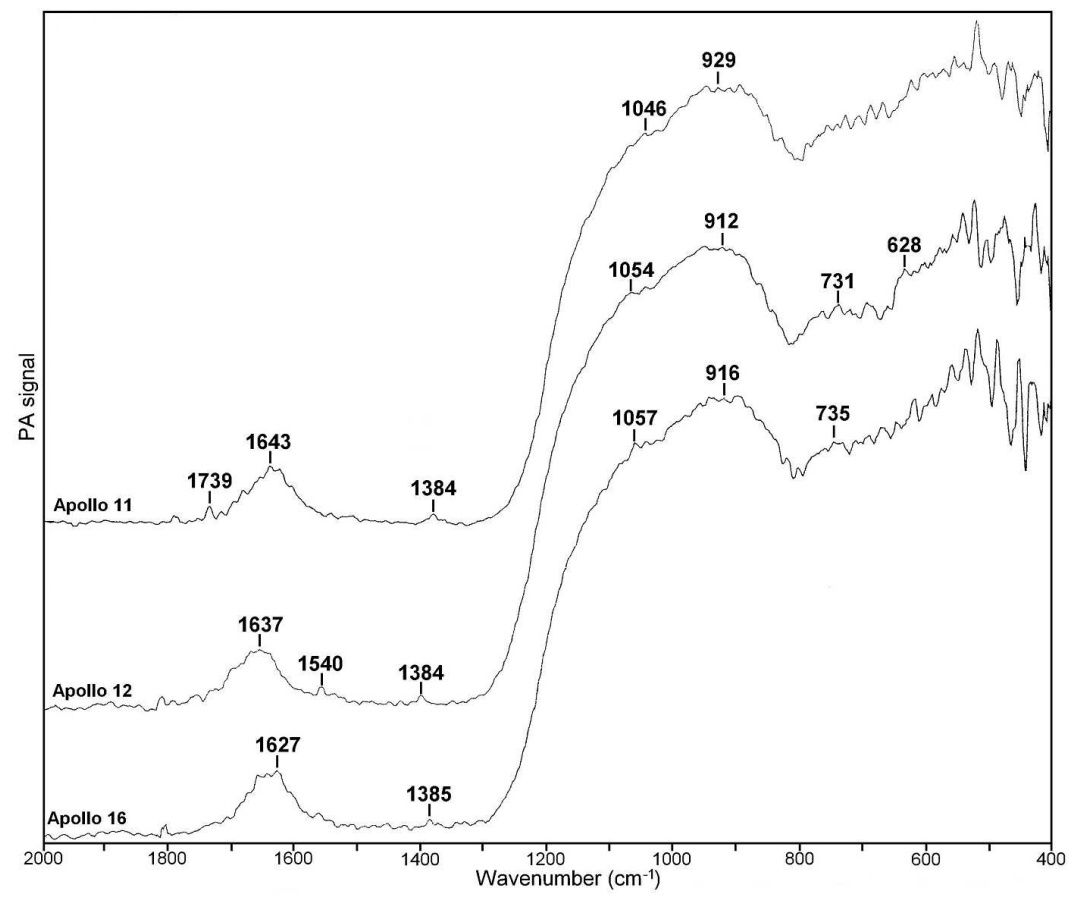

Fig. 3. FT-IR/PA spectra of Lunar regolith samples in the $2000-400 \mathrm{~cm}^{-1}$ region.

TABLE IV

Main minerals detected in the investigated samples [5].

\begin{tabular}{c|l}
\hline \hline Mission & \multicolumn{1}{|c}{ Minerals and their chemical formula } \\
\hline Apollo 11 & $\begin{array}{l}\text { ilmenite }\left(\mathrm{FeTiO}_{3}\right), \text { pyroxene }\left((\mathrm{Ca}, \mathrm{Mg}, \mathrm{Fe})_{2} \mathrm{Si}_{2} \mathrm{O}_{6}\right), \text { anorthite }\left(\mathrm{CaAlSi}_{2} \mathrm{O}_{8}\right), \\
\text { traces of Olivine }\left((\mathrm{Mg}, \mathrm{Fe})_{2} \mathrm{SiO}_{4}\right)\end{array}$ \\
\hline Apollo 12 & olivine, magnetite $\left(\mathrm{Fe}_{3} \mathrm{O}_{4}\right)$, pyroxene, anorthite \\
\hline Apollo 16 & anorthite, olivine, pyroxene
\end{tabular}

\section{Conclusions}

FT-IR/PAS technique in the studies conducted was a supplementary one. The presence of adsorbed water and silica materials was confirmed. Moreover, the analysis of very specific and rare samples verified the importance and the unique character of the spectroscopic method used [8]. Spectroscopic measurements conducted allow to detect the presence of contaminants. 


\section{References}

[1] M. Anand, L.A. Taylor, M.A. Nazarov, J. Shu, H.-K. Mao, R.J. Hemley, Proc. Natl. Acad. Sci. USA 101, 6847 (2004).

[2] http://www-curator.jsc.nasa.gov/lunar/.

[3] A.L. Turkevich, Acc. Chem. Res. 6, 81 (1973).

[4] E. Robens, A. Bischoff, A. Schreiber, A. Dąbrowski, K.K. Unger, Appl. Surf. Sci. 253, 5709 (2007).

[5] G. Socrates, Infrared and Raman Characteristic Group Frequencies. Tables and Charts, 3rd ed., Wiley, Chichester 2001.

[6] E. Mendyk, private information.

[7] E. Palomba, A. Rotundi, L. Colangeli, Icarus 182, 68 (2006).

[8] J. Ryczkowski, Catalysis Today 124, 11 (2007). 